Article

\title{
Intelligent System for Interactive Teaching through Videogames
}

\author{
Diego Robles and Christian G. Quintero M. \\ Department of Electrical and Electronics Engineering, Universidad del Norte, 081007 Barranquilla, Colombia; \\ roblesad@uninorte.edu.co \\ * Correspondence: christianq@uninorte.edu.co
}

Received: 31 March 2020; Accepted: 20 April 2020; Published: 28 April 2020

check for updates

\begin{abstract}
Education, videogames, and intelligent systems are all relevant topics for researchers. Determining means of improving academic performance using a range of techniques and tools is an important challenge. However, while there are currently websites and multimedia resources that help students to improve their knowledge on specific topics, these lack in not having intelligent agents that can evaluate students and recommend materials to suit the difficulty that a user is having in a given subject. In this sense, this paper aims at developing an intelligent system that allows interactive teaching in basic education using videogames. In particular, high school students' skills in basic mathematical operations with fractions were used for testing experimentally the approach. An intelligent system was developed using computational techniques such as fuzzy logic and case-based reasoning to evaluate user performance and recommend additional study material according to the specific challenges from the given educational game. The use of the games was supported by ICT (information and communication technologies) tools on a web platform. Such a developed platform was tested by 206 high school students, who played 5400 games in total. The students showed an improvement of around $14 \%$ in the topics covered. The results indicate that the implementation jointly of videogames and intelligent systems allows users to improve their performance in the given topics.
\end{abstract}

Keywords: education; videogames; intelligent systems; fuzzy logic; case-based reasoning; ICT; interactive education

\section{Introduction}

\subsection{Education and Videogames}

The ability of education to produce learning depends on how the information is transmitted [1]. It has been proven that when a subject is presented with the appropriate didactic tools, the knowledge will persist, and students will remember it longer than with standard methods [1].

This study considers intelligent systems and their impact on the educational sector to strengthen skills in users, through the use of videogames complemented by information and communication technologies (ICT) as a model of interactive teaching.

At present, videogames in educational environments offer a range of benefits that can strengthen multisensory capabilities in interactive education. Thus, for instance, videogames have been developed to assess children with autism spectrum disorder and to reinforce positive behaviors and rehabilitate them into standard interactions [2]. Such systems can simulate other environments to help control different user behaviors. Videogames can recreate scenographies that, in addition to teaching, strengthening, and developing new strategies, offer people a range of learning environments from home concepts to school $[3,4]$. 
The researchers report several actions that videogames can enable a user to take [5]: producing, teaching, motivating, socializing, communicating, and learning from different cultures. It is possible to find videogames that focus on education, health, science, and research. Videogames are widely used as part of an educational environment. In this sense, the main objective of educational videogames is to bring people to understand a range of tools embodied in a game to improve their cognitive abilities [5].

\subsection{Education and Intelligent Systems}

Intelligent tutoring systems can transmit knowledge and allow people to develop several skills in a specific field [6]. For an intelligent system to provide specific information, it must be adapted to the actions, needs, preferences, and habits of the users, incorporating the patterns of behavior that can be used to determine the classification of the different users' profiles. Education-focused game systems provide virtual environments, use multimedia interaction, and train practical skills to present and reinforce knowledge in students [7]. In such interactive systems, enriching experiences can be created during training. Researchers argue that educational game systems can support the learning process and help students with their academic tasks [8]. Thus, they should monitor the users' learning development to propose specific recommendations to improve their academic performance.

In summary, videogames are a powerful support tool for different application domains such as learning musical instruments, flight simulators, teaching people, recovery therapies, among others. Education is a relevant sector for the implementation of these technologies to strengthen and improve concepts. In this sense, the next section exposes the proposed intelligent system for interactive teaching supported by videogames. The system is installed on a web platform using ICT, where it allows users to interact, showing their current progress with suggestions for continuous improvement.

\section{Methods}

\subsection{Proposed System}

Figure 1 shows the proposed general model of the system. Such a system evaluates user knowledge of the topics handled. As the user interacts with the system, it stores all player-generated information and later decodes, analyzes, and evaluates it by using an intelligent system. Finally, the system displays all the statistical information calculated during the user's progress and provides suggestions that consider being convenient to reinforce the subjects addressed in the games. In particular, high school students' skills in basic mathematical operations with fractions are used for testing experimentally the approach.

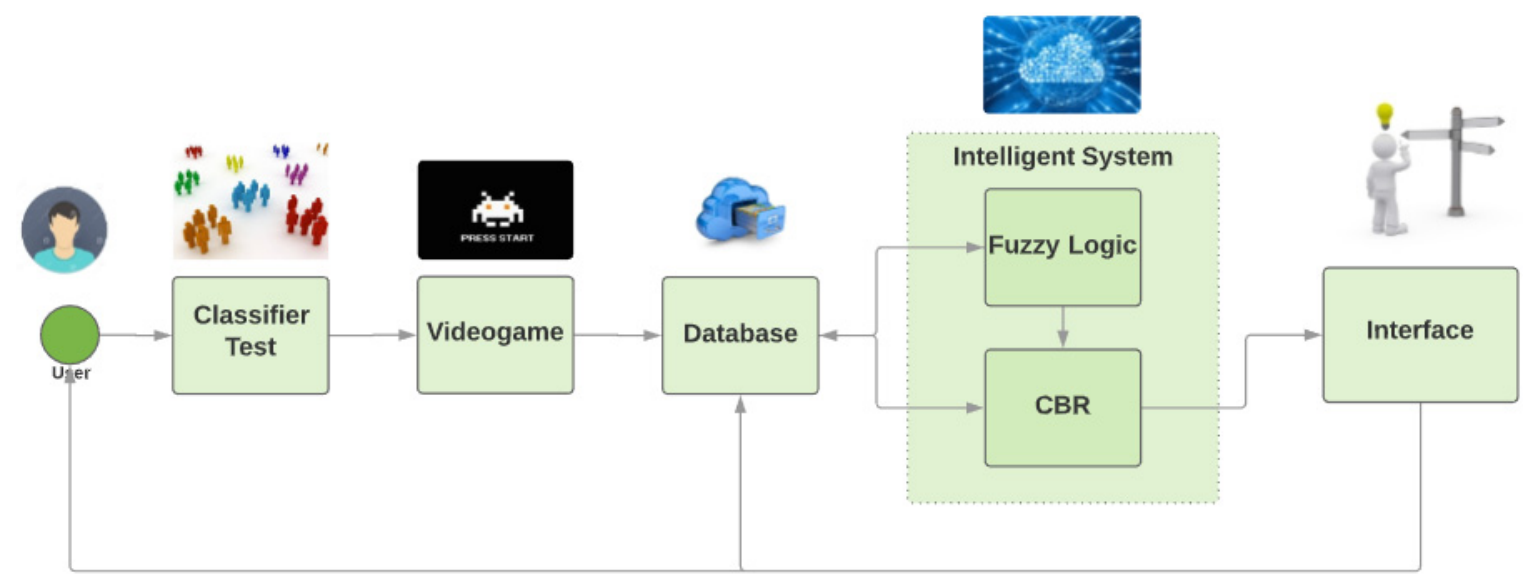

Figure 1. Model of the proposed system. 


\subsection{Choice of Videogames}

To choose a videogame for study, a range of factors are taken into account, such as the type of game, difficulty, duration, aesthetics, and competitiveness. Table 1 summarizes the videogames selection analysis.

Educational electronic games that focused on mathematics incorporating essential subjects, such as the basic operations of integers and fractional numbers, are reviewed. 2D-linear videogames are used to provide quick and accurate results. Such type of games allows capturing more quickly the user data in each game and controlling the actions of people in its use.

Table 1. Choice of mathematical videogames.

\begin{tabular}{|c|c|c|c|c|c|c|c|}
\hline No. & Name & $\begin{array}{l}\text { Type of Video } \\
\text { Game }\end{array}$ & Difficulty & Time (Sec) & Aesthetics & Competitive & Fun \\
\hline 1 & What's your sign? & Linear - 2D & Hard & 60 & OK & - & - \\
\hline 2 & Monkey Math Balance & Linear - 2D & Easy & 120 & OK & - & OK \\
\hline 3 & $\begin{array}{c}\text { Speedway Fractions Adding } \\
\text { Fractions }\end{array}$ & Linear - 2D & Medium & 64 & OK & OK & OK \\
\hline 4 & Compare Fractions & Linear - 2D & Easy & 65 & OK & OK & - \\
\hline 5 & SnowSprint Multiply Fractions & Linear - 2D & Medium & 64 & OK & OK & OK \\
\hline 6 & Sowing Grass & Linear - 2D & Medium & - & OK & - & - \\
\hline 7 & Fraction Matcher & Linear - 2D & Medium & - & OK & - & OK \\
\hline 8 & Number climb & Linear - 2D & Hard & - & OK & - & - \\
\hline 9 & $\begin{array}{c}\text { Martian Hoverboards Algebra } \\
\text { Evaluating Expressions }\end{array}$ & Linear - 2D & Medium & 81 & OK & OK & OK \\
\hline 10 & Puppy Chase Fractions To Decimals & Linear - 2D & Medium & 64 & OK & OK & OK \\
\hline
\end{tabular}

The difficulty of the topics addressed in the electronic games must vary according to the age of the users. For this reason, videogames that can adapt to the learning speed of the current user should be used.

Duration is a key element for each game, as it is linked to multiple factors, including the ability to capture data and user attention. The latter is important because the performance of multiple repetitions in an extensive game can cause user fatigue. Therefore, videogames are chosen with an average playtime between 60 and $85 \mathrm{~s}$.

Each videogame is required to have a user-friendly design and color scheme. At the same time, the games are required to be competitive to ensure a positive experience among the users and to result in a desire to play again.

According to the above, the following videogames were selected:

\subsubsection{SpeedWay Fractions (Adding Fractions)}

This is a mathematical racing videogame where users operate a car that continues to move forward so long as the questions shown on the screen are correctly answered (see Figure 2A). If a question is incorrectly answered, the vehicle slows down. The questions consist of basic operations related to the addition and subtraction of homogeneous fractions. Users who respond correctly to more questions will be in a better position than opposing users.

\subsubsection{SnowSprint (Multiply Fractions)}

This is a mathematical videogame where correct answers to on-screen fractional number multiplication questions propel the user's vehicle (see Figure 2B). The higher the number of correct responses, the more likely it is that the user finishes the game.

\subsubsection{Puppy Chase (Fractions to Decimals)}

This is a competitive videogame in which users convert mixed numbers into decimals (see Figure $2 \mathrm{C}$ ). As the player correctly solves the questions shown on the screen, the character within 
the videogame moves forward at higher and higher speed, ultimately overtaking the opponents and taking a top position in the game.

\subsubsection{Martian Hoverboards (Algebra Evaluating Expressions)}

In this game, the user must solve a combination of addition, subtraction, and multiplication problems presented by the videogame (see Figure 2D). For correct user responses, the characters are propelled faster in a competition for the first position.

All videogames used in this research can be found on the Internet and are produced by Arcademics [9].

\section{A. Speedway fractions adding fractions}

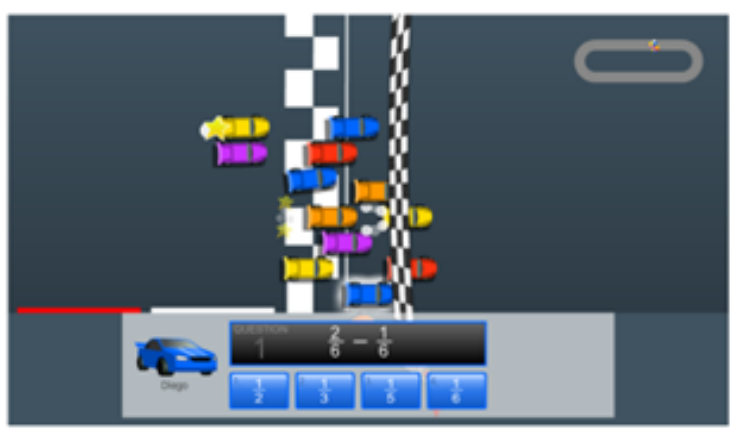

C. Puppy chase fractions to decimals

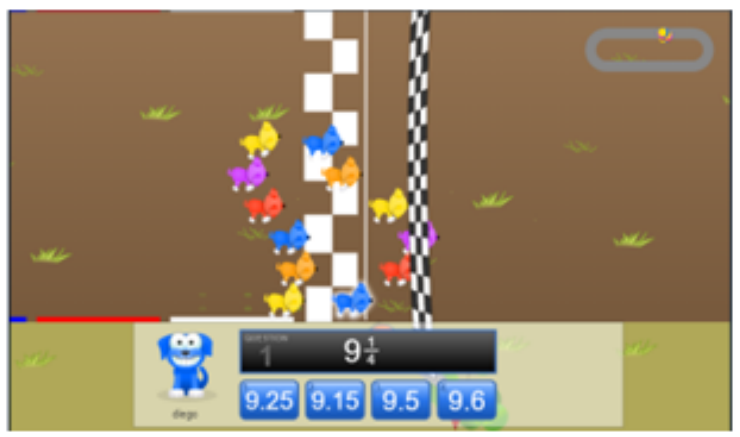

\section{B. SnowSprint multiply fractions}

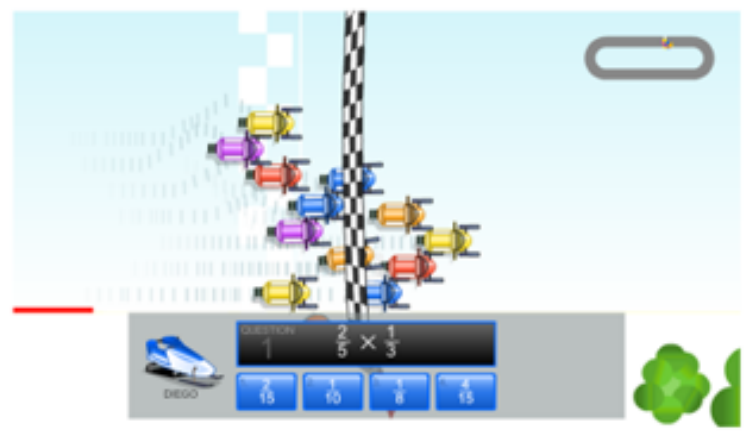

D. Martian hoverboards algebra evaluating expressions

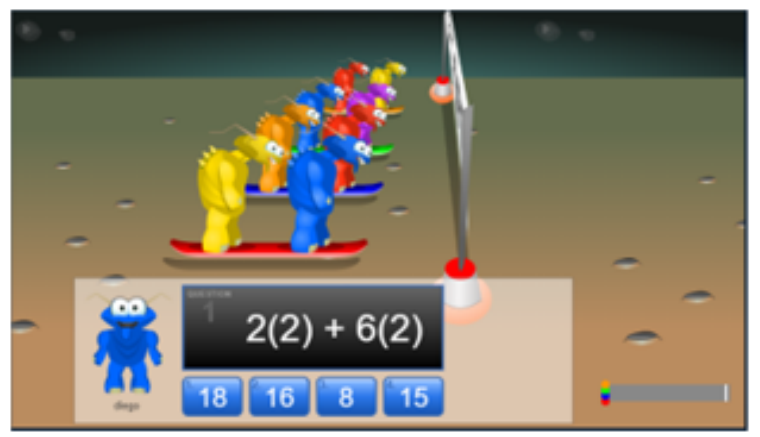

Figure 2. Selected videogames in this approach.

\subsection{Intelligent System}

This is a trained system that can solve problems without the need for human supervision. Intelligent systems exhibit behavior similar to human intelligence [10]. They are characterized by the representation, processing, and modification of a problem's information and the consequent improvement of their reasoning through their experience. As the system has new experiences, it can interact with different environments and adapts to novel situations.

There are a variety of ways of developing computational intelligence. For this study, fuzzy logic and case-based reasoning (CBR) are considered.

\subsubsection{Fuzzy Logic}

Fuzzy logic makes it possible to produce a quick response despite blurred or inaccurate information. This approach imitates the decision-making procedures employed by a person seeking to obtain accurate results from ambiguous data. 
This technique can use data that is less precise than that which could be used by conventional logic, which requires accurate and complete data. The advantage of fuzzy logic is that it allows for formalizing expressions with a high degree of ambiguity through membership functions [11].

- Membership Functions: The variables for correct answers, incorrect answers, and playtime obtained for these games are taken as fuzzy entries, where their respective membership functions are created. To obtain a metric in which the user's knowledge can be classified, using the values obtained in the input variables, a membership function called Performance is created.

- Correct Fuzzy Set: To create membership functions, it is necessary to make games with different users and classify the results. Figure 3A shows the ranges of correct answers obtained through experimentation: 0-10 (poor), 9-15 (medium), and 14 or more (good) questions.

- Incorrect Fuzzy Set: The membership function for questions incorrectly answered is classified into the following ranges: $0-5$ (good), 3-11 (medium), and 10 or more (poor) (see Figure 3B).

- Time Fuzzy Set: This membership function for playtime is classified by the following ranges: 0-58 (good), 58-64 (medium), and 64 or more (poor) seconds (see Figure 3C).

- Performance Fuzzy Set: The membership function for the response variable is defined by the ranges 0-5 (beginner), 5-10 (medium), and 10 or more (pro) (see Figure 3D).

- Fuzzy Rules: The fuzzy rules are created from expert knowledge in the study topics. The fuzzy rules are elaborated using the Mamdani method, which allows the creation of a condition for a direct relation of the inputs with the output of the system. If one or more additional inputs exist, they can be associated with logical operators and can be related to the output variable.

So that for a system to make decisions based on fuzzy rules, the membership degree of the fuzzy set must be examined [12]. The value of the system response variable is determined through defuzzification, that is, by converting the values from the linguistic variables into numerical values. Each fuzzy rule generates a set that relates to the membership function for each element. All output sets coming from the rules are combined into a single set, where the value of the response variable corresponds to the centroid value of the figure obtained [12].

With the fuzzy sets established in inputs and outputs, fuzzy rules can be created. Rules for which a relationship could not be created are eliminated. Tables 2 and 3 present the rules obtained for system functioning.

Table 2. Fuzzy rules for playtime and correct answers.

\begin{tabular}{ccccc}
\hline \multirow{2}{*}{ Inputs } & \multicolumn{3}{c}{ Correct } \\
\cline { 2 - 5 } & Poor & Medium & Good \\
\hline \multirow{2}{*}{ Time } & poor & beginner & beginner & beginner \\
good & beginner & medium & medium \\
& - & pro & pro \\
\hline
\end{tabular}

Table 3. Fuzzy rules for playtime and incorrect answers.

\begin{tabular}{ccccc}
\hline \multirow{2}{*}{ Inputs } & \multicolumn{3}{c}{ Incorrect } \\
\cline { 2 - 4 } & & Poor & Medium & Good \\
\hline \multirow{2}{*}{ Time } & poor & beginner & beginner & - \\
medium & beginner & beginner & medium \\
& - & medium & pro \\
\hline
\end{tabular}


A. Correct

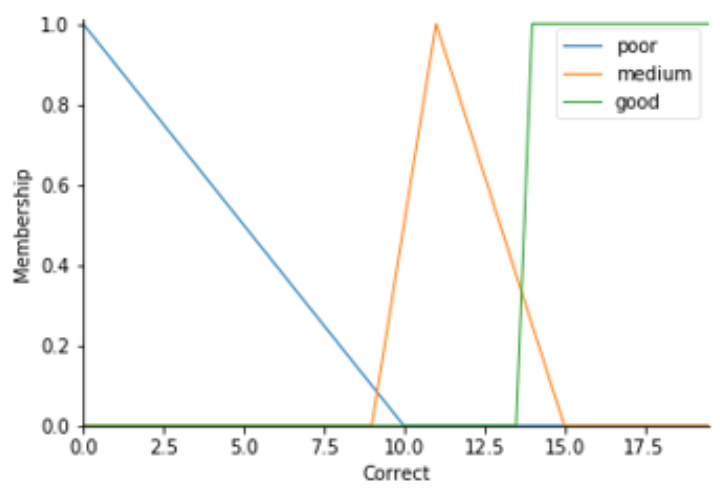

C. Time

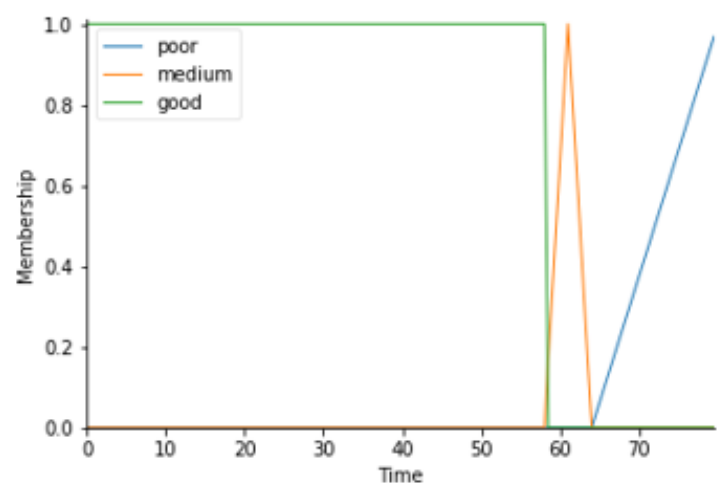

B. Incorrect

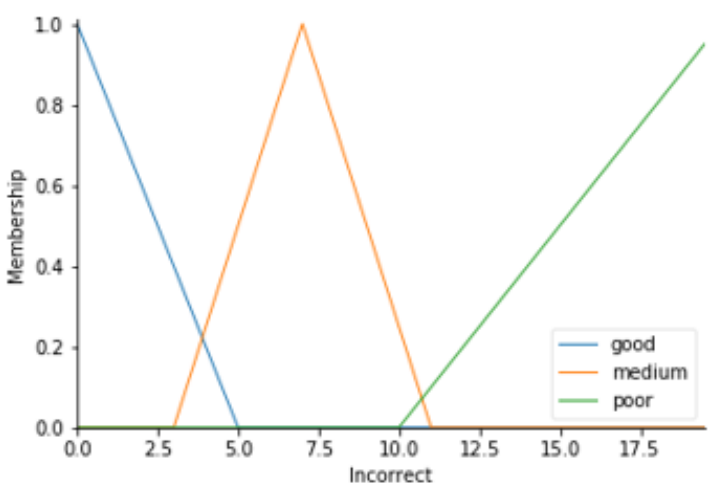

D. Performance

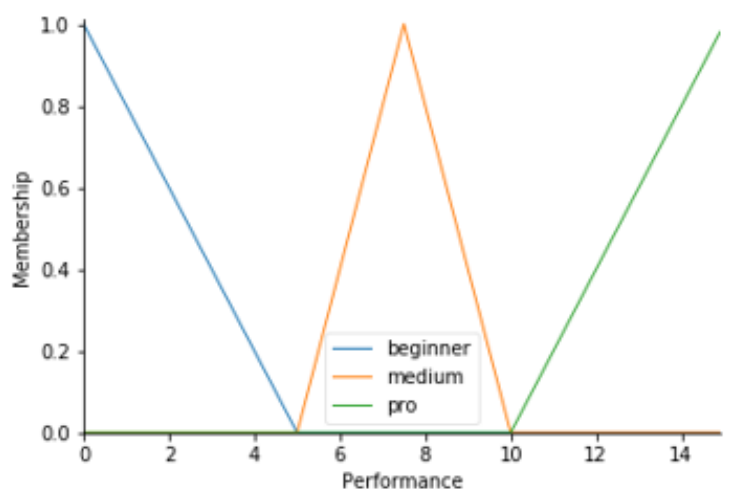

Figure 3. Membership functions for the user's knowledge evaluation.

- Fuzzy Profiles: To ensure optimum representation of user performance, a minimum number of games are played by each user. The fuzzy system requires a minimum of 10 games played per pair of videogames, i.e., five games per game. The videogame pairs are as follows: 1. SpeedWay SnowSprint. 2. Puppy Chase - Martian Hoverboards.

After the required number games are completed, the system calculates the performance for each game and averages the most recent five records. Two fuzzy responses for each videogame are calculated. These final variables enable us to classify the user in the following profiles:

a. Beginner: This profile is obtained when the category calculated by the system for the user in both videogames is Beginner, implying that the user does not meet minimum performance expectations.

b. Medium: This profile is divided into two, Medium 1 and Medium 2. For Medium 1, the user performs better in SpeedWay or Puppy Chase than in the paired game SnowSprint or Martian Hoverboards. For Medium 2, the user performs better in SnowSprint or Martian Hoverboards than in the paired game SpeedWay or Puppy Chase.

c. Pro: This profile is obtained when the outputs for both games are advanced.

Tables 4 and 5 present the game profiles according to the fuzzy logic results. 
Table 4. Profiles obtained according to performances on SpeedWay and SnowSprint.

\begin{tabular}{ccc}
\hline SpeedWay & SnowSprint & Profile \\
\hline Beginner & Beginner & Beginner \\
Pro & Medium & Medium 1 \\
Pro & Beginner & Medium 1 \\
Medium & Beginner & Medium 1 \\
Medium & Pro & Medium 2 \\
Beginner & Pro & Medium 2 \\
Beginner & Medium & Medium 2 \\
Medium & Medium & Medium 2 \\
Pro & Pro & Pro \\
\hline
\end{tabular}

Table 5. Profiles obtained according to performances on Puppy Chase and Martian Hoverboards.

\begin{tabular}{ccc}
\hline Puppy Chase & Martian H. & Profile \\
\hline Beginner & Beginner & Beginner \\
Pro & Medium & Medium 1 \\
Pro & Beginner & Medium 1 \\
Medium & Beginner & Medium 1 \\
Medium & Pro & Medium 2 \\
Beginner & Pro & Medium 2 \\
Beginner & Medium & Medium 2 \\
Medium & Medium & Medium 2 \\
Pro & Pro & Pro \\
\hline
\end{tabular}

After the profile classification is completed, the system saves the game information with the defuzzified values (performance) for each videogame to the database. The maximum value of the defuzzified output according to the configuration established in the fuzzy logic of the Python library used is 13.27. Equation (1) presents the performance value to the user in the range of $0-100 \%$.

$$
\text { Performance }=\frac{\text { fuzzy value } * 100 \%}{13.27},
$$

\subsubsection{Case-Based Reasoning}

CBR has high similarity to human problem-solving reasoning, because the methodology it uses to solve new cases is based on its previous experiences. If the experience recovered does not fit the case, the system must propose new solutions to solve the problem.

A case is described as an approach to a problem with a range of factors and the solution to that problem. In this sense, the case base relates to the set of all previous cases stored in the system that features a given solution to multiple problems.

The CBR analyzes the case and chooses the solution that would adapt better to the proposed problem. If no solution is found, it seeks another from its base of cases that better matches the problem.

To update the system, the CBR stores useful data and solutions for the current cases $[13,14]$. Here, the CBR consists of a cycle called the four Rs [15]:

- Retrieve: To retrieve the nearest case, it is necessary to know the performance value of the fuzzy system for the user $(\mathrm{V})$. The system retrieves the closest cases $\left(\mathrm{C}_{\mathrm{i}}\right)$ using the upper limit $(\mathrm{S})$ (Equation (2)) and the lower limit (L) (Equation (3)) with a range of $10 \%$. Then all yields are searched within the limits found.

$$
\begin{aligned}
& S=V+(V * 10 \%), \\
& L=V-(V * 10 \%),
\end{aligned}
$$


Equation (4) is used to select the retrieved cases.

$$
C_{i}=L<V<S,
$$

After calculating the number of cases within the limits, the closest case (M) is identified. For this, Equation (5) is evaluated.

$$
M=\min \left(V-C_{i}\right) .
$$

- Reuse: After $\mathrm{M}$ is found, the information stored in the system database is retrieved. The case is composed of the following variables: case number, user profile, user performance, and user improvement recommendation.

- Revise: At this stage, it is verified that the recommendation matched the user need. Additionally, other backup recommendations are presented if the first does not satisfy the user. For cases where the user does not accept the recommendation, the CBR withdraws all the suggestions and replaces them with new ones. This process is repeated until the problem is solved or the number of recommendations is exhausted, and the initial suggestions are then shown again.

- Retain: Where users report that the case is a solution to the problem, the system remains the case, and the case base is not updated. Otherwise, the CBR continues to send recommendations until the user decides that it has already solved the issue. The CBR automatically stores a new case, taking as information the performance of the user and the recommended suggestion. In this way, the system is updated to be able to respond to future problems.

The CBR makes recommendations to the user depending on the profile obtained from the games played. These suggestions include external didactic material, such as web pages and tutorial videos, to provide to people to reinforce mathematical topics with a deficiency.

- Recommendations: The material to be recommended consists of interactive websites and didactic videos accessible through the YouTube platform, where mathematical topics related to each videogame are discussed. The external material has 40 recommendations, divided among the following topics: eight (8) for the addition of fractions, eight (8) for the subtraction of fractions, eight (8) for multiplication of fractions, eight (8) for combinations of addition, subtraction, and multiplication of fractions, four (4) for basic operations of integers, and four (4) for the conversion of mixed numbers to decimals.

The CBR presents different recommendations depending on the given user's profile. For example, users with a Medium 1 profile, that is, who has better performance in SpeedWay than in SnowSprint, receives recommendations for multiplication of fractions. Table 6 shows which topics should be suggested, depending on the profile obtained.

Table 6. Recommendations according to the user's profile.

\begin{tabular}{ccc}
\hline Video Game & Profile & Recommendations \\
\hline & Beginner & Addition, subtraction, multiplication of fractions \\
SpeedWay/SnowSprint & Medium 1 & Multiplication of fractions \\
& Medium 2 & Addition and subtraction of fractions \\
& Pro & None \\
\hline & Beginner & Basic operations and fraction conversion \\
Puppy Chase/Martian Hoverboards & Medium 1 & Basic operations \\
& Medium 2 & Fraction conversion \\
& Pro & None \\
\hline
\end{tabular}

\section{Results}

SpeedWay, SnowSprint, Puppy Chase, and Martian Hoverboards are racing games in which the user must answer a series of basic math operations questions. The precise questions vary randomly 
in each game, such that the user is not likely to be exposed to the same conditions in two games. Although the user indeed wins when he or she achieves first place in a competition, each particular play session is better than another when a greater number of correct responses are reported, fewer incorrect answers are given, and less time is taken. Taking into account this idea, intelligent systems are integrated to achieve improvements in user performance. Thus, the videogames are evaluated using different variables, such as the time at the end of the race, rate of questions per minute, and accuracy, among others. However, another variable, called performance, is created to be used by the intelligent system. This variable integrates time data, the number of correct answers and the number of incorrect answers. In this way, the system assesses the same information for all the tested videogames.

The method of evaluation to measure user performance is initially related to a preliminary test at the moment of registering in the platform (see Figure 4).

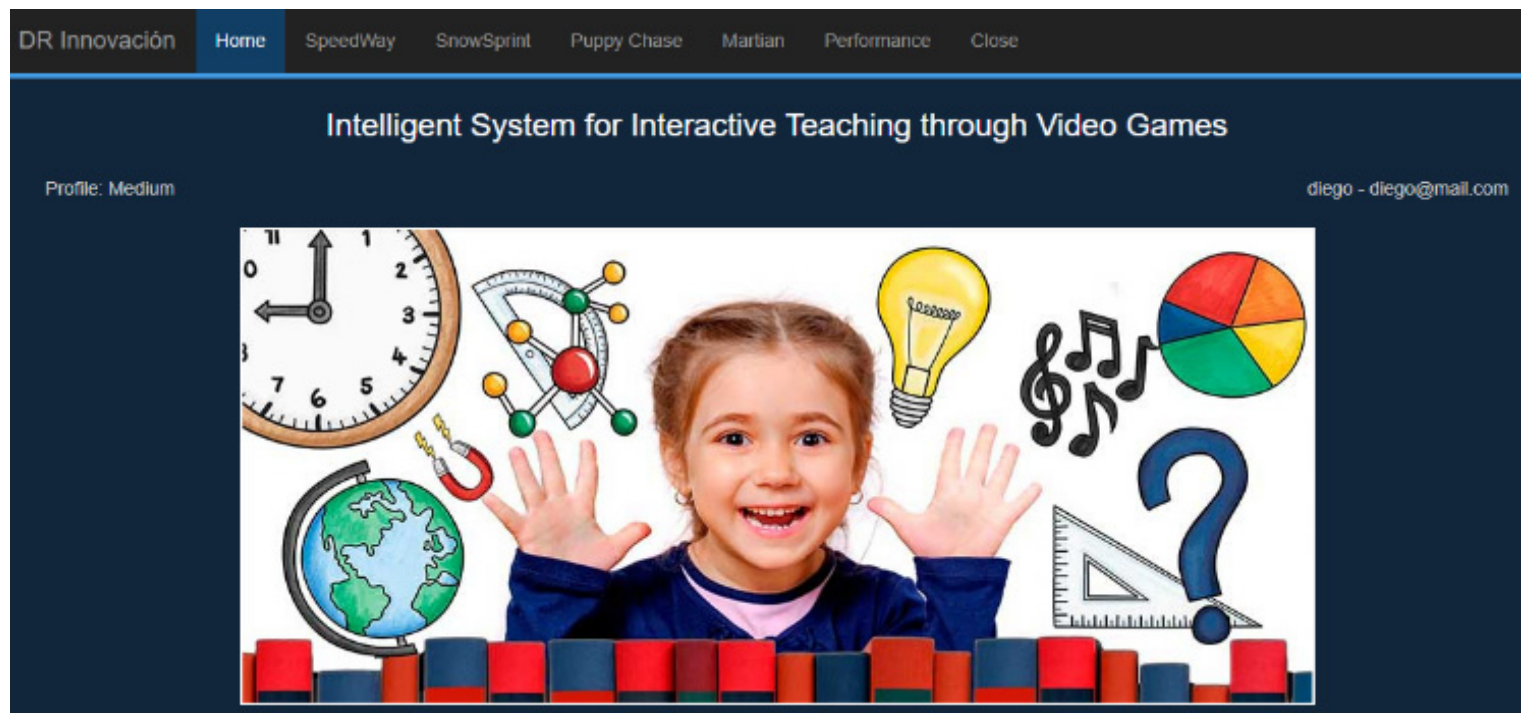

Figure 4. Developed platform.

The results are stored in the database after the videogame is played to be analyzed and evaluated by the intelligent system. Once this is completed, the intelligent system recommends possible improvement actions according to the profile obtained and the previous experiences with similar performance. The system then provides statistics on the progress achieved by the user through the games stored in the database.

The tests were carried out on high school students from Colegio del Sagrado Corazón, Calle 74 (see Figure 5), which is located in Barranquilla, Colombia. The platform has 206 users.

Figure 6 shows a sample analysis of user performance in the games on the platform. This analysis develops statistical data presenting user averages for the most recent five games, the general average per game, the game average for all users, standard deviations, minimum and maximum values for all realized yields, number of games played, and interquartile ranges. Besides, comparison charts for videogames, game history, and system recommendations are provided. Figure 7 shows several examples of the websites and videos that the system recommends to users. 

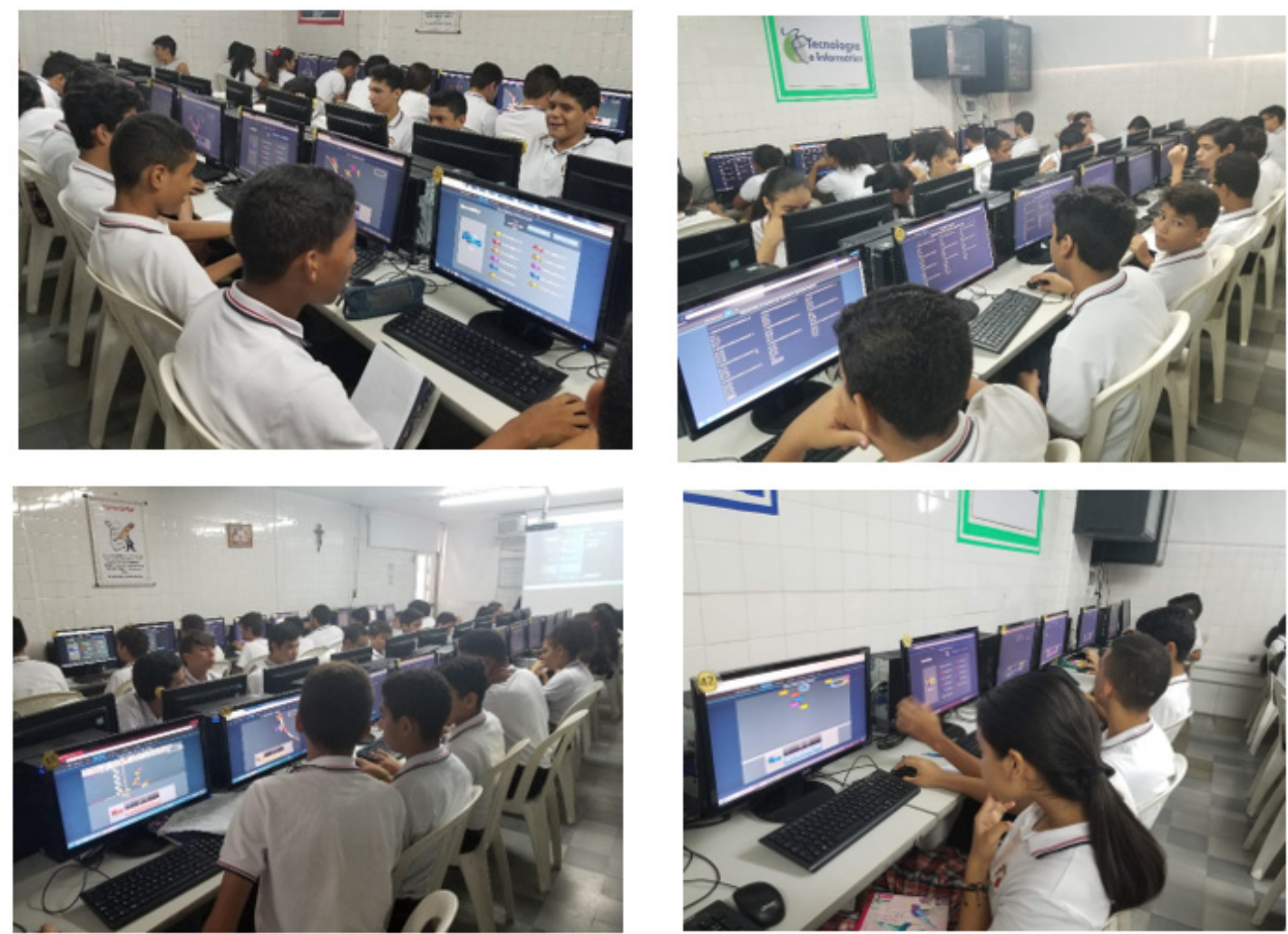

Figure 5. Students using the proposed platform.

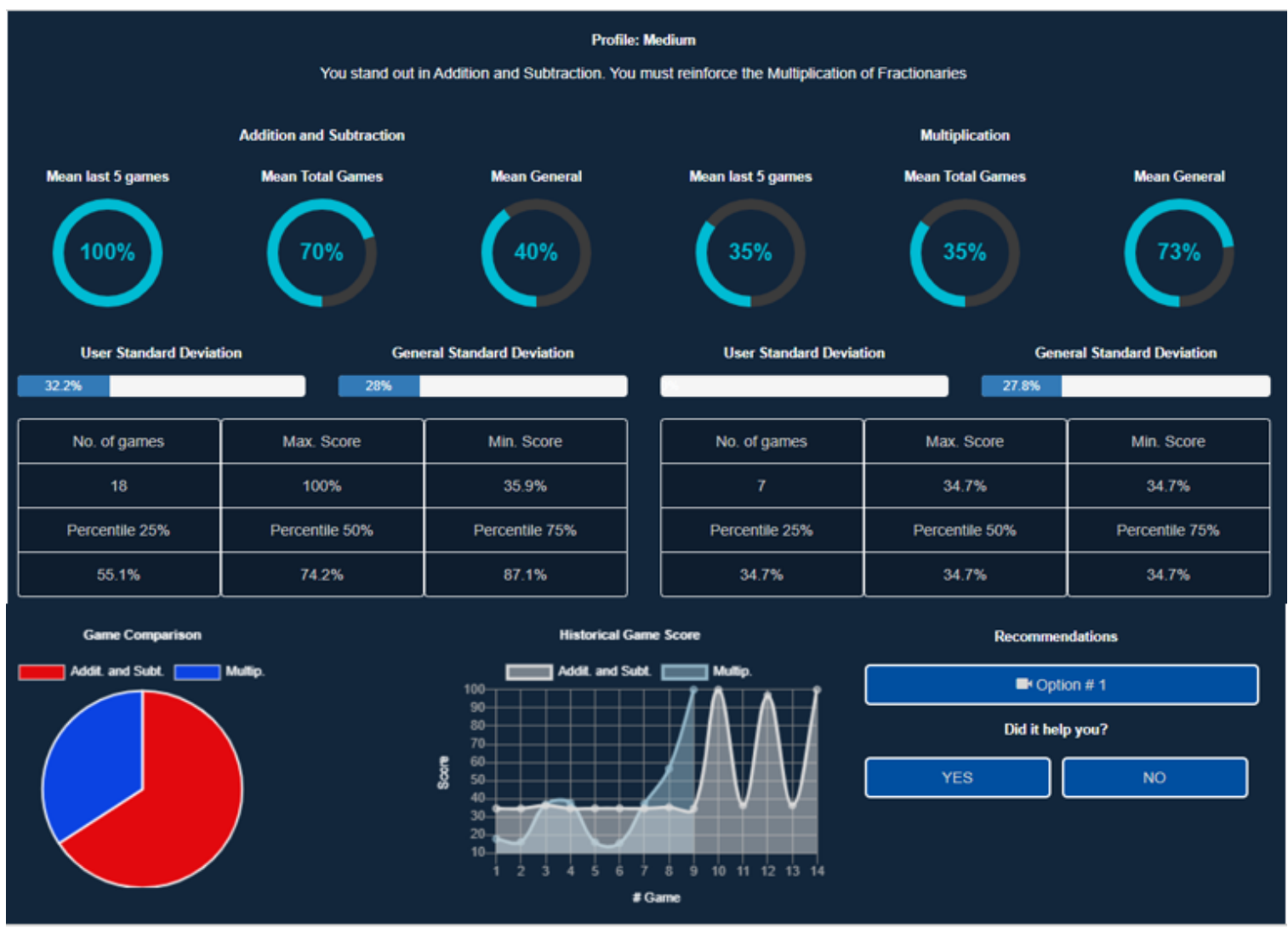

Figure 6. User statistical performance on the proposed platform. 
A. Web page No. 1

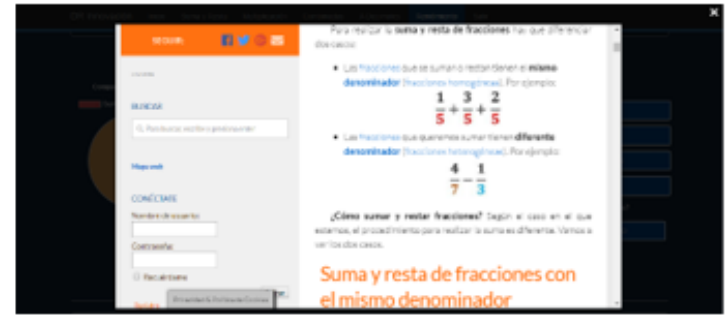

C. Video No. 1

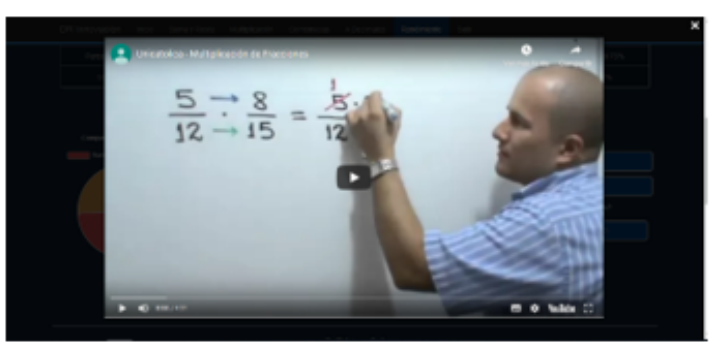

B. Web page No. 2

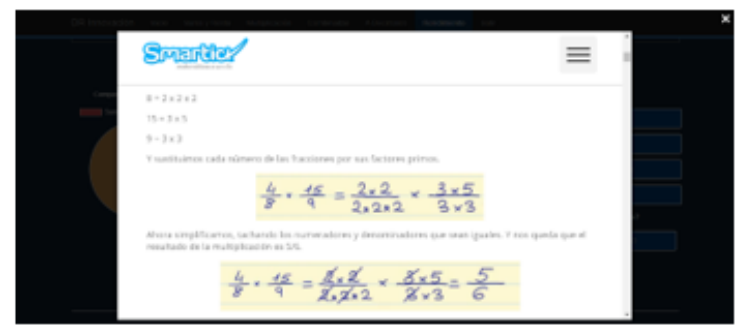

D. Video No. 2

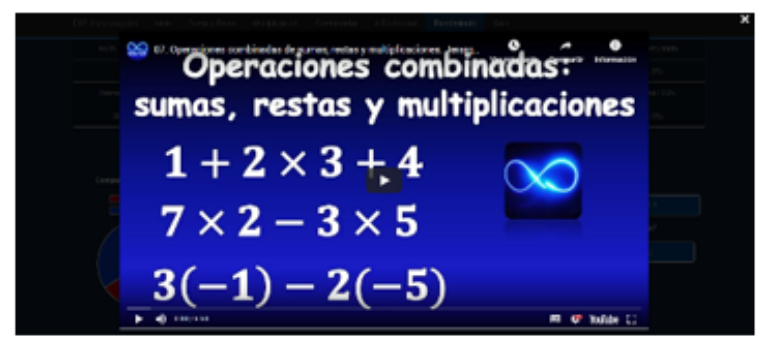

Figure 7. Examples of external material suggested to the users.

Table 7 shows the results (mean and standard deviation) from 140 users for the SpeedWay videogame. The initial performance (the first five games) is 32.7\%. After using the platform (45 days) taking the intelligent system recommendations, the most recent five games are taken as a measure and the group average is then $41.03 \%$ (an increase in performance of $8.3 \%$ ). Table 8 shows that the students' progress is $8.01 \%$ for the SnowSprint videogame. Table 9 shows the best performance achieved (an increase of $14.83 \%$ ) for the Puppy Chase videogame. Table 10 shows an increase of $6.07 \%$ for the Martian Hoverboards videogame. Results are then validated following the most common methods of the state of the art $[2,7,16-19]$.

Table 7. Result for SpeedWay in the first and final five games.

\begin{tabular}{cccc}
\hline \multicolumn{4}{c}{ Game 1 - Speedway Fractions Adding Fractions } \\
\hline & First (\%) & Last (\%) & Improvement (\%) \\
\hline Mean & 32.70 & 41.03 & 8.32 \\
Deviation & 11.29 & 12.86 & \\
\hline Sample & 700 & & \\
No. of Students & 140 & & \\
\hline
\end{tabular}

Table 8. Results for SnowSprint in the first and final five games.

\begin{tabular}{cccc}
\hline \multicolumn{4}{c}{ Game 2 - SnowSprint } \\
\hline & First (\%) & Last (\%) & Improvement (\%) \\
\hline Mean & 68.67 & 76.69 & 8.018 \\
Deviation & 22.72 & 21.68 & \\
\hline Sample & 700 & & \\
No. of Students & 140 & & \\
\hline
\end{tabular}


Table 9. Results for Puppy Chase in the first and final five games.

\begin{tabular}{|c|c|c|c|}
\hline \multicolumn{4}{|c|}{ Game 3 - Puppy Chase Fractions To Decimals } \\
\hline & First (\%) & Last (\%) & Improvement (\%) \\
\hline Mean & 69.76 & 75.1491 & 14.38 \\
\hline Deviation & 22.861 & 17.7621 & \\
\hline Sample & 435 & & \\
\hline No. of Students & 87 & & \\
\hline
\end{tabular}

Table 10. Results for Martian in the first and final five games.

\begin{tabular}{|c|c|c|c|}
\hline \multicolumn{4}{|c|}{ Game 4 - Martian Hoverboards Algebra Evaluating Expressions } \\
\hline & First (\%) & Last (\%) & Improvement (\%) \\
\hline Mean & 58.94 & 65.01 & 6.07 \\
\hline Deviation & 23.88 & 23.24 & \\
\hline Sample & 480 & & \\
\hline No. of Students & 96 & & \\
\hline
\end{tabular}

\section{Discussion}

The results for each videogame show that the implementation of the intelligent system with the two computational techniques allows the user to obtain better performance in the addressed topics.

The proposed model allows the use of the same fuzzy system structure and the same CBR scheme for the four videogames. Then, it is possible to use the same metric for different games and perform similar tests for the corresponding analysis. Finally, the results of the tests allow for concluding that the combination of intelligent systems, videogames, and ICT improves learning in the users of the system. The intelligent system takes advantage of the student's assessed level and the previous experiences of users stored in the case database to provide more accurate recommendations according to the current level of the student. Videogames provide a suitable environment for interaction where students learn in a fun and competitive way. ICTs integrate the overall system into a friendly platform accessible from anywhere via the Internet. Thus, the objectives of this research are successfully met, and it is found possible to implement an intelligent system that allows interactive teaching in basic education using videogames.

\section{Conclusions}

A new digital platform was developed to reinforce mathematical knowledge in people through videogames and intelligent systems. This platform was evaluated by high school students and judged to offer a new alternative to allow users to increase their mathematical skills.

This study was focused on the development of an intelligent system according to the proposed model. In the future, we will seek to integrate new computational techniques with complementary information from users to bring more specific suggestions. Another goal for future work is to increase the range of videogames to test the capabilities and characteristics of the system. Finally, the implementation of the proposed approach in different educational institutions will benefit more students around.

Author Contributions: Conceptualization, D.R. and C.G.Q.M.; methodology, D.R. and C.G.Q.M.; software, D.R.; validation, D.R.; formal analysis, D.R. and C.G.Q.M.; investigation, D.R. and C.G.Q.M.; resources, D.R.; data curation, D.R.; writing — original draft preparation, D.R. and C.G.Q.M.; writing—review and editing, D.R. and C.G.Q.M.; visualization, D.R.; supervision, C.G.Q.M.; project administration, C.G.Q.M. All authors have read and agreed to the published version of the manuscript.

Funding: This research received no external funding. 
Acknowledgments: This work was supported by Universidad del Norte, Barranquilla - Colombia. Special thanks to Colegio Del Sagrado Corazón - Calle 74 for the continuous support in this study.

Conflicts of Interest: The authors declare that there are no conflicts of interest regarding the publication of this paper.

\section{References}

1. Kandlhofer, M.; Steinbauer, G.; Hirschmugl-Gaisch, S.; Huber, P. Artificial intelligence and computer science in education: From kindergarten to university. In Proceedings of the 2016 IEEE Frontiers in Education Conference (FIE), Erie, PA, USA, 12-15 October 2016; pp. 1-9.

2. Kohli, M.; Kohli, S. Increasing target behavior of children with developmental disorders by designing innovative multistage tablet games. In Proceedings of the 2016 IEEE Region 10 Humanitarian Technology Conference (R10-HTC), Agra, India, 21-23 December 2016; pp. 1-6.

3. Bringas, J.A.S.; León, M.A.C.; Cota, I.E.; Carrillo, A.L. Development of a videogame to improve communication in children with autism. In Proceedings of the 2016 XI Latin American Conference on Learning Objects and Technology (LACLO), San Carlos, Costa Rica, 3-7 October 2016; pp. 1-6.

4. Janssen, A.; Shaw, T.; Goodyear, P. Using video games to enhance motivation states in online education: Protocol for a team-based digital game. JMIR Res. Protoc. 2015, 4, e114. [CrossRef] [PubMed]

5. Janarthanan, V. Serious video games: Games for education and health. In Proceedings of the 2012 Ninth International Conference on Information Technology-New Generations, Las Vegas, NV, USA, 16-18 April 2012; pp. 875-878.

6. Toala, R.; Durães, D.; Novais, P. Human-Computer Interaction in Intelligent Tutoring Systems. In Proceedings of the International Symposium on Distributed Computing and Artificial Intelligence, Ávila, Spain, 26-28 June 2019; Springer: Cham, Switzerland, 2019; pp. 52-59.

7. Butz, B.P.; Miller, S.M.; Duarte, M.; Wlodarczyk, B.; Cooper, R.A. Work in Progress: An intelligent tutoring system for forensic biology. In Proceedings of the Frontiers in Education 36th Annual Conference, San Diego, CA, USA, 27-31 October 2006; pp. 19-20.

8. Todorov, J.; Stoyanov, S.; Valkanov, V.; Daskalov, B.; Popchev, I. Learning Intelligent System for Student Assistance-LISSA. In Proceedings of the 2016 IEEE 8th International Conference on Intelligent Systems (IS), Sofia, Bulgaria, 4-6 September 2016; pp. 753-757.

9. Arcade Academics, Fun Learning, Arcademic Skill Builders-Math Games, Language Arts Games, and much more. Available online: https://www.arcademics.com/ (accessed on 31 March 2020).

10. Zhang, B.; Jia, J. Evaluating an intelligent tutoring system for personalized math teaching. In Proceedings of the 2017 International Symposium on Educational Technology (ISET), Hong Kong, China, 27-29 June 2017; pp. 126-130.

11. Gonzalez, C.I.; Melin, P.; Castro, J.R.; Mendoza, O.; Castillo, O. An improved sobel edge detection method based on generalized type-2 fuzzy logic. Soft Comput. 2016, 20, 773-784. [CrossRef]

12. Martínez, M.P.; Gabriel, C.P.C.; Gabriel Filho, L.R.A.; Junior, S.S.B.; Bednaski, A.V.; Quevedo-Silva, F.; Correa, C.M.; Silva, D.; Padgett, R.C.M.L. Fuzzy inference system to study the behavior of the green consumer facing the perception of greenwashing. J. Clean. Prod. 2019, 242, 116064. [CrossRef]

13. Morales Luna, G. Introducción a la Lógica Difusa; Centro de Investigación y Estudios Avanzados: Mexico City, México, 2002.

14. MATLAB \& Simulink, Mamdani and Sugeno Fuzzy Inference Systems-MathWorks América Latina. Available online: https:/la.mathworks.com/help/fuzzy/types-of-fuzzy-inference-systems.html (accessed on 30 March 2020).

15. Aljuboori, A. Enhancing case-based reasoning retrieval using classification based on associations. In Proceedings of the 2016 6th International Conference on Information Communication and Management (ICICM), Hatfield, UK, 29-31 October 2016; pp. 52-56.

16. Rodrigo, M.M.T.; d Baker, R.S.; D’Mello, S.; Gonzalez, M.C.T.; Lagud, M.C.; Lim, S.A.; Macapanpan, A.F.; Pascua, S.A.M.S.; Santillano, J.Q.; Sugay, J.O.; et al. Comparing learners' affect while using an intelligent tutoring system and a simulation problem solving game. In Proceedings of the International Conference on Intelligent Tutoring Systems, Montreal, QC, Canada, 11-15 June 2018; Springer: Berlin/Heidelberg, Germany, 2018; pp. 40-49. 
17. Abramovich, S.; Schunn, C.; Higashi, R.M. Are badges useful in education? It depends upon the type of badge and expertise of learner. Educ. Technol. Res. Dev. 2013, 61, 217-232. [CrossRef]

18. Bourgeois, M.; Cubillos, C.; Mellado, R.; Roncagliolo, S.; Sentis, F. Ashy.alRescate (): A videogame for developing basic object oriented programming skills. In Proceedings of the 201837th International Conference of the Chilean Computer Science Society (SCCC), Santiago, Chile, 5-9 November 2018; pp. 1-7.

19. Mateos, M.J.; Muñoz-Merino, P.J.; Kloos, C.D.; Hernández-Leo, D.; Redondo-Martínez, D. Design and evaluation of a computer based game for education. In Proceedings of the 2016 IEEE Frontiers in Education Conference (FIE), Erie, PA, USA, 12-15 October 2016; pp. 1-8.

(C) 2020 by the authors. Licensee MDPI, Basel, Switzerland. This article is an open access article distributed under the terms and conditions of the Creative Commons Attribution (CC BY) license (http://creativecommons.org/licenses/by/4.0/). 